\title{
CARACTERÍSTICAS SENSORIAIS DE OVOS ARMAZENADOS EM DIFERENTES EMBALAGENS SOB TEMPERATURA AMBIENTE
}

\author{
SENSORIAL CHARACTERISTICS OF EGGS STORED AT ROOM TEMPERATURE \\ UNDER DIFFERENT PACKING CONDITIONS
}

\author{
Scatolini-Silva, A.M. ${ }^{1 *}$; Borba, H. ${ }^{1 \text { A }}$; Giampietro-Ganeco, A. ${ }^{1 B}$; Lima, T.M.A. ${ }^{1 \mathrm{C}}$; \\ Dourado, R.C. ${ }^{1 \mathrm{D}}$; Berton, M.P. ${ }^{1 \mathrm{E}}$ e Souza, P.A. ${ }^{1 \mathrm{~F}}$ \\ ${ }^{1}$ Faculdade de Ciências Agrárias e Veterinárias (FCAV/UNESP). Jaboticabal-SP. Brasil. \\ *alinescatolini@yahoo.com.br; Ahiras@fcav.unesp.br; Balgiamp@yahoo.com.br; ctmall77@ig.com.br; \\ Dritazootecnista@hotmail.com; Emapberton@yahoo.com.br; Fpasoz@fcav.unesp.br
}

\section{PalaVRas ChaVe ADICIONAIS}

Filme aparência. Higienização. PVC. Vácuo.

\section{RESUMO}

O presente estudo objetivou avaliar as características sensoriais de ovos, de casca branca, higienizados ou não, armazenados em diferentes condições de embalagens, sob temperatura ambiente. Foram utilizados 200 ovos, distribuídos em um DIC em esquema fatorial $3 \times 2 \times 4+1$, sendo três condições de embalagens (filme PVC, vácuo parcial e vácuo parcial com sequestrantes de gás oxigênio), quatro períodos de armazenamento (7, 14,21 e 28 dias), higienizados ou não, e testemunha (ovos frescos), com 4 repetições 2 ovos cada, e 10 julgadores. Foram realizadas avaliações visuais e olfativas dos ovos nos diferentes períodos de armazenamento, por análise descritiva quantitativa (ADQ) em escala não estruturadas de $9 \mathrm{~cm}$. A condição de vácuo parcial mostrou que os ovos foram rejeitados pela aparência externa e interna, e odor externo da casca, principalmente se não higienizados. E ainda nesta condição, foram percebidos odores azedos e gemas opacas. $\mathrm{Na}$ condição de vácuo com sachês sequestrantes de $\mathrm{O}_{2}$ foram notados odores de podre, principalmente quando higienizados. Conclui-se que, ovos embalados em filme de PVC mostraram melhores aceitações em todos os atributos avaliados, independente de terem sido higienizados.

\section{SUMMARY}

This study evaluated the sensory characteristics of white-shelled eggs, sanitized or not,

\section{Additional KEYWORDS}

Appearance.PVC film. Sanitization. Vacuum.

stored under different packaging conditions at room temperature. There were used 200 eggs, distributed in a completely randomized design in a $3 \times 2 \times 4+1$ factorial arrangement, three packaging conditions (PVC film, partial vacuum, partial vacuum with oxygen gas absorber), storage period $(7,14$, 21 and 28 days), sanitized or not, and control (fresh eggs), with four repetitions of two eggs, and ten judges. The eggs were visually and olfactorily evaluated in different periods of storage, by Quantitative Descriptive Analysis (QDA) by means of unstructured scales of $9 \mathrm{~cm}$. Partial vacuum condition showed that the eggs were rejected by the external and internal appearance and external odor, especially if not sanitized. In this condition were observed sour smells and opaque egg yolks. In vacuum with $\mathrm{O}_{2}$ sachets absorbers were noted sour smells, especially if sanitized. It can be concluded that eggs packed in PVC film, sanitized or not, showed the best acceptances in all attributes.

\section{INTRODUÇÃO}

Na produção de alimentos, a excelência da matéria prima é fator indispensável para garantir um produto final seguro. Dessa forma, o ovo de galinha é largamente utilizado para consumo direto ou como ingrediente de produtos que podem não sofrer tratamento térmico antes do consumo ou 
conter microrganismos contaminantes termorresistentes e podem ser veiculadores de microrganismos, inclusive patogênicos (Frazier e Westhoff, 2000).

Fatores como qualidade da matéria prima, condições ambientais, características e condições técnicas de higienização dos equipamentos são pontos importantes na prevenção de agentes toxinfecciosos veiculados por ovos e seus produtos. Entretanto, nenhum desses fatores supera a importância das técnicas de manipulação e formas de acondicionamento deste produto.

No que diz respeito ao armazenamento do ovo, alguma deterioração em odor e sabor podem ocorrer, pois odores desagradáveis podem ser absorvidos pelo ovo, se não houver cuidado de evitar sua ocorrência no armazenamento (Griswold, 1972). O odor e o sabor azedo característico aparecem, possivelmente, pelas leves modificações que ocorrem na proteína e na gordura do ovo. Além das mudanças inevitáveis, que se operam durante o envelhecimento do ovo, também ocorre, às vezes, a deterioração microbiana. Quando o ovo é posto, seu conteúdo geralmente é estéril, mas, à medida que o ovo se resfria, os microrganismos podem invadí-lo através da casca porosa.

Normalmente as trocas gasosas através da casca, ou seja, a evaporação, pode ser controlada aumentando-se a umidade do local de armazenamento para $85 \%$, mas isto ocasionaria a putrefação por fungos. O que pode ser evitado ao adicionar $\mathrm{CO}_{2}$ na atmosfera do armazenamento. Se for usado $60 \%$ de dióxido de carbono, a umidade pode ser mantida em $96 \%$, reduzindo a evaporação a valores pequenos, juntamente com a prevenção do desenvolvimento de fungos. Com apenas $2,5 \%$ de $\mathrm{CO}_{2}$ e $80 \%$ de umidade relativa, impede-se o desenvolvimento de fungos, mas a velocidade de evaporação será relativamente rápida (Hawthorn, 1983).

Devido a tais dificuldades, controlar a contaminação em ovos destinados ao comércio apresenta-se como um grande desafio para os produtores. Desinfecções regulares das instalações e equipamentos devem ser feitas, com o objetivo de controlar e garantir a descontaminação, minimizando o problema. Assim como, buscar condições ideais de armazenamento e transporte (Fraga et al., 2007).

$\mathrm{O}$ armazenamento do ovo fresco deve ser cuidadoso, devido às perdas que ocorrem na qualidade, principalmente por ação de microrganismo, perda de pesos e todos os processos de desintegração químicos e físicos, que têm influência adversa sobre o estado original de frescor e sobre a palatabilidade (Soares e Siewerdt, 2005). Os ovos se alteram por putrefação bacteriana e fúngica, processo que se retarda mediante armazenamento em baixas temperaturas ou por tratamento da casca para fechar os poros (Hawthorn, 1983).

A casca do ovo é uma embalagem natural, o qual está pronto para ser comercializado e, para isso, deve ser resistente para não sofrer nenhum dano físico, nem mesmo pequenas fissuras (Kussakawa et al., 1998). Mesmo assim, o acondicionamento em embalagens ideais para preservar o produto íntegro por longos períodos de armazenamento, sujeito às oscilações de temperatura e umidade, é imprescindível até atingir o consumidor final.

Dessa forma, para o consumidor, a embalagem é frequentemente a primeira fonte de informação sobre a cadeia de produção, pois indica segurança e responsabilidade do determinado produto, sendo um importante fator de confiança. E, neste contexto, a análise sensorial constitui uma ferramenta importante para averiguar a qualidade de produtos, isto é, avaliar se a estocagem e o acondicionamento foram eficazes em manter as propriedades sensoriais dos ovos.

Mediante o exposto, o presente estudo objetivou avaliar as características sensoriais de ovos in natura, higienizados ou não, armazenados em diferentes condições de embalagens sob temperatura ambiente. 


\section{CARACTERÍSTICAS SENSORIAIS DE OVOS EM DIFERENTES EMBALAGENS}

\section{MATERIALE MÉTODOS}

O experimento foi conduzido no Laboratório de Tecnologia dos Produtos de Origem Animal (T.P.O.A.) do Departamento de Tecnologia da Faculdade de Ciências Agrárias e Veterinárias da UNESP, Câmpus de Jaboticabal-SP, Brasil.

Foram utilizados 1200 ovos frescos de casca branca todos sem trincas e classificados como grandes, de aves da mesma idade, linhagem e sistema de criação, provenientes de poedeiras leves, Hy Line W-36, com 56 semanas de idade. E para a determinação das características sensoriais foram analisados 200 ovos.

Metade dos ovos foi coletada, nos meses de janeiro a fevereiro de 2010, antes da higienização realizada nas granjas, e a outra metade após tal procedimento. Ecom relação à higienização dos ovos, os mesmos foram lavados mecanicamente em água clorada (50 ppm) a $35-40{ }^{\circ} \mathrm{C}$ (Brasil, 1990).

Após tais procedimentos, todos realizados na Cooperativa Agrícola da cidade de Guatapará -SP, Brasil, os ovos foram levados para o Laboratório de T.P.O.A. da FCAV em Jaboticabal em aproximadamente uma hora, sob condições de temperatura ambiente. Em seguida, realizou-se a distribuição em 24 tratamentos, ou seja, foram divididos em dois grupos (higienizados e não higienizados), distribuídos em bandejas de PET (politereftalato de etileno) para 1 dúzia de ovos e submetidos a três condições de embalagens utilizadas: filme PVC, vácuo parcial e vácuo com sachês sequestrantes de gás oxigênio.

Dessa forma, um terço das bandejas com 1 dúzia de ovos foram embalados em filme plástico de poli cloreto de vinila (PVC), e os outros dois terços foram recobertos por sacolas plásticas Protervac ${ }^{\circledR}(0,1 \mathrm{~mm},<85$ $\mathrm{O}_{2} \mathrm{cc} / \mathrm{m}^{2} / 24 \mathrm{~h}$ a $23{ }^{\circ} \mathrm{C}$ ) com as seguintes dimensões: $20 \mathrm{~cm}$ (largura) x $51 \mathrm{~cm}$ (comprimento) x $180 \mu$ (espessura). Nestas últimas, foi realizado o vácuo parcial em embaladora a vácuo Selovac® 200 B.
Os sachês utilizados para sequestrar o $\mathrm{O}_{2}$ tinham capacidade de absorver $50 \mathrm{cc}$ de gás oxigênio, sendo elaborado por um composto químico em pó, a base de óxido de ferro e zeolite. Assim, a quantidade de sachês sequestrantes de $\mathrm{O}_{2}$ no interior das embalagens foi estipulada de acordo com a perda de peso dos ovos (Scatolini-Silva et al., 2010), as dimensões da embalagem e a capacidade de absorção dos mesmos (conforme especificações do fabricante).

Os ovos foram armazenados durante quatro períodos $(7,14,21$ e 28 dias), sob temperatura ambiente, e as análises iniciais dos ovos frescos higienizados (testemunha) se procederam imediatamente após o embalamento (dia 0$)$.

Nas condições em que o experimento foi realizado, as médias, mínimas e máximas, das temperaturas foram de $21,2{ }^{\circ} \mathrm{C}$ e $33{ }^{\circ} \mathrm{C}$, respectivamente, com média de umidade relativa de $57 \%$.

Uma equipe composta com 10 indivíduos foi previamente selecionada e treinada para possuírem habilidade em verbalizar as sensações e trabalhar em grupo, para demonstrar a reprodutibilidade da análise. O treinamento dos julgadores seguiu método tradicional descrito por Dutcosky (1996).

Foi utilizado um delineamento inteiramente casualizado em esquema fatorial $3 \times 2 \times 4+1$ (tipos de embalagem, higienizados ou não higienizados, e períodos de armazenamento + testemunha-ovos fres$\cos$ ), com 4 repetições de 2 ovos cada, com 10 julgadores. Foi verificada a homogeneidade da variância (através do teste de Bartlett), em seguida as médias dos resultados obtidos foram comparadas pelo teste de Tukey a $5 \%$ de significância, utilizando o GLM Procedure do sistema operacional SAS (1999).

Foram avaliados os ovos nos diferentes períodos de armazenamento, por análise descritiva quantitativa (ADQ) em escala não estruturadas de $9 \mathrm{~cm}$, ancoradas um pouco aquém dos extremos com termos que indicaram a intensidade dos atributos avaliados 
como desenvolvido pela Tragon Corporation por Stone et al. (1974), citado por Dutcosky (1996). Foram realizadas avaliações apenas visuais e olfativas. Para a realização dos testes, foram fornecidas as amostras de ovos in natura (ovos inteiros para avaliação da casca externa, e em seguida quebrados e realizadas as avaliações internas) de acordo com cada tratamento, sendo que todos os avaliadores julgavam os mesmos ovos. Participaram da análise sensorial 10 julgadores treinados previamente.
As características sensoriais avaliadas foram observadas por Scatolini-Silva et al. (2010), os ovos foram avaliados externamente quanto à aparência (embolorada ou não) e odor (mofo ou não) da casca, e internamente quanto à aparência (embolorada ou não) e odor (mofo ou não) da casca; ainda internamente, no ovo como um todo foram avaliados aparência (opaco ou não) e odor (característico de bolor, azedo e podre), no albúmen e na gema também foi avaliada a aparência (opaco ou não). Sendo que os extremos indicavam a presença total

Tabela I. Médias das notas ${ }^{1}$ obtidas para as avaliações da casca, segundo os atributos de aparência externa e interna e odor externo e interno, dos ovos armazenados em diferentes embalagens. (Averages obtained for evaluations of the attributes external and internal appearance and external and internal smell of egg shells stored in different packaging).

\begin{tabular}{|c|c|c|c|c|}
\hline & Aparência externa & Odor externo & Aparência interna & Odor interno \\
\hline \multicolumn{5}{|c|}{ Testemunha vs. Fatorial } \\
\hline Testemunha & $9,00^{A}$ & $9,00^{A}$ & $9,00^{A}$ & 9,00 \\
\hline Fatorial & $6,64^{\mathrm{B}}$ & $8,18^{\mathrm{B}}$ & $7,73^{\mathrm{B}}$ & 8,79 \\
\hline Teste F & $79,51^{* *}$ & $8,87^{* *}$ & $18,12^{\star *}$ & $0,90^{\mathrm{NS}}$ \\
\hline \multicolumn{5}{|c|}{ Armazenamento em dias $(\mathrm{P})$} \\
\hline 7 & - & - & - & 9,00 \\
\hline 14 & - & - & - & 8,68 \\
\hline 21 & - & - & - & 8,69 \\
\hline 28 & - & - & - & 8,82 \\
\hline Teste F & - & - & - & $3,06^{\mathrm{NS}}$ \\
\hline \multicolumn{5}{|l|}{ Embalagem (E) } \\
\hline Filme & - & - & - & 8,84 \\
\hline Vácuo parcial & - & - & - & 8,66 \\
\hline Vácuo+Seq. $\mathrm{O}_{2}$ & - & - & - & 8,88 \\
\hline Teste F & - & - & - & $2,48^{\mathrm{NS}}$ \\
\hline \multicolumn{5}{|l|}{ Higienização (H) } \\
\hline Sim & 6,65 & - & - & 8,73 \\
\hline Não & 6,64 & - & - & 8,63 \\
\hline Teste $\mathrm{F}$ & $0,00^{\mathrm{NS}}$ & - & - & $2,38^{\mathrm{NS}}$ \\
\hline F Interação PxE & $5,11^{\star *}$ & $68,75^{\star *}$ & $15,18^{* *}$ & $1,03^{\mathrm{NS}}$ \\
\hline F Interação PxH & $0,97^{\mathrm{NS}}$ & $0,35^{\mathrm{NS}}$ & $18,53^{\star *}$ & $0,64^{\mathrm{NS}}$ \\
\hline F Interação ExH & $3,05^{\mathrm{NS}}$ & $3,16^{*}$ & $18,57^{\star \star}$ & $2,07^{\mathrm{NS}}$ \\
\hline F Interação PxExH & $1,90^{\mathrm{NS}}$ & $0,38^{\mathrm{NS}}$ & $20,78^{* *}$ & $0,80^{\mathrm{NS}}$ \\
\hline CV (\%) & 10,15 & 8,64 & 9,93 & 6,29 \\
\hline
\end{tabular}

Archivos de zootecnia vol. 62, núm. 240, p. 546. 


\section{CARACTERÍSTICAS SENSORIAIS DE OVOS EM DIFERENTES EMBALAGENS}

(nota 1) ou ausência total (nota 9) da característica analisada.

Cada repetição foi avaliada em um período (manhã e tarde), assim cada julgador recebeu 12 ovos durante dois dias consecutivos, por período de análise sensorial (manhã e tarde), em cada período de armazenamento. E no dia 0, oito ovos.

\section{RESULTADOSEDISCUSSÃO}

Os resultados para as análises sensorial dos ovos de cascas branca estão dispostos nas tabelas I a VIII. Na tabela I encontramse as médias obtidas pelo julgamento da equipe treinada para as avaliações externa e interna dos ovos, tais como: aparência e odor. Houve interação entre os fatores período de armazenamento $\mathrm{x}$ embalagem para as características de aparência externa e interna e para odor externo; entre os fatores período de armazenamento x higienização apenas para a característica aparência interna; e entre embalagem x higienização para odor externo e aparência interna, e todos os desdobramentos encontram nas tabelas II a IV. Os três fatores estudados (período $\mathrm{x}$ embalagem $x$ higienização) interagiram para

Tabela II. Desdobramento da interação entre período de armazenamento (dias) e embalagens para aparência externa ${ }^{1}$ da casca dos ovos. (Interaction sliced of storage period and packaging for the egg shell external appearance).

\begin{tabular}{lcccc}
\hline & \multicolumn{4}{c}{ Período de armazenamento } \\
Embalagem & 7 & 14 & 21 & 28 \\
\hline Filme & $8,89^{\mathrm{Aa}}$ & $8,75^{\mathrm{Ab}}$ & $8,93^{\mathrm{Aa}}$ & $8,66^{\mathrm{Ab}}$ \\
Vácuo parcial & $2,32^{\mathrm{Bbc}}$ & $3,43^{\mathrm{Ba}}$ & $2,71^{\mathrm{Bab}}$ & $1,79^{\mathrm{Bc}}$ \\
Vácuo+Seq. $\mathrm{O}_{2}$ & $9,00^{\mathrm{Aa}}$ & $8,46^{\mathrm{Aab}}$ & $8,71^{\mathrm{Aab}}$ & $8,08^{\mathrm{Ab}}$
\end{tabular}

A,BNa mesma coluna, médias seguidas de letras maiúsculas iguais não diferem entre si pelo teste de Tukey (5\%); a,b,cna mesma linha, médias seguidas de letras minúsculas iguais não diferem entre si pelo teste de Tukey (5\%). ${ }^{1} 1=$ presença total... $9=$ ausência total.
Tabela III. Desdobramentos das interações entre periodo de armazenamento (dias) e embalagens, e entre embalagens e higienização para odor ${ }^{l}$ externo da casca dos ovos. (Interactions for storage period x packaging, and packaging $\mathrm{x}$ sanitation for the external egg shell smell).

\begin{tabular}{|c|c|c|c|c|}
\hline & \multicolumn{4}{|c|}{ Período de armazenamento } \\
\hline & 7 & 14 & 21 & 28 \\
\hline \multicolumn{5}{|l|}{ Embalagem } \\
\hline Filme & $9,00^{\mathrm{Aa}}$ & $8,86^{\mathrm{Aa}}$ & $8,86^{\mathrm{Aa}}$ & $8,83^{\mathrm{Aa}}$ \\
\hline Vácuo parcia & $8,82^{\mathrm{Aa}}$ & $7,39^{\mathrm{Bb}}$ & $8,14^{\text {Aab }}$ & $2,75^{\mathrm{Bc}}$ \\
\hline \multirow[t]{3}{*}{ Vácuo+Seq. C } & $\mathrm{O}_{2} 9,00^{\mathrm{Aa}}$ & $8,78^{\mathrm{Aa}}$ & $8,86^{\mathrm{Aa}}$ & $8,92^{\mathrm{Aa}}$ \\
\hline & \multicolumn{4}{|c|}{ Embalagem } \\
\hline & Filme & $\begin{array}{l}\text { Vácuo } \\
\text { parcia }\end{array}$ & & $\begin{array}{l}\text { Vácuo+ } \\
\text { Seq. } \mathrm{O}_{2}\end{array}$ \\
\hline \multicolumn{5}{|l|}{ Higienização } \\
\hline Sim & $8,87^{\mathrm{Aa}}$ & $7,05^{\mathrm{Ab}}$ & & $8,85^{\mathrm{Aa}}$ \\
\hline Não & $8,87^{\mathrm{Aa}}$ & $6,50^{\mathrm{Ab}}$ & & $8,93^{\mathrm{Aa}}$ \\
\hline
\end{tabular}

A,BNa mesma coluna, médias seguidas de letras maiúsculas iguais não diferem entre si pelo teste de Tukey (5\%); a,b,cna mesma linha, médias seguidas de letras minúsculas iguais não diferem entre si pelo teste de Tukey $(5 \%) .{ }^{1} 1=$ presença total... $9=$ ausência total

a característica aparência interna da casca.

Pode-se observar na tabela I que a higienização não influenciou $(p>0,05)$ a aparência externa e o odor interno da casca, e o odor interno da casca não foi influenciado $(p>0,05)$ por nenhum dos fatores estudados.

O desdobramento da interação entre período de armazenamento e embalagens para a aparência externa da casca é apresentado na tabela II, onde pode-se notar que a aparência externa da casca foi pior para os ovos embalados em condição de vácuo em todos os períodos armazenados, e nessa condição tiveram suas cascas emboloradas já aos 7 dias de estocagem, sendo que as piores notas foram aos 28 dias de armazenamento. Em todos os períodos 


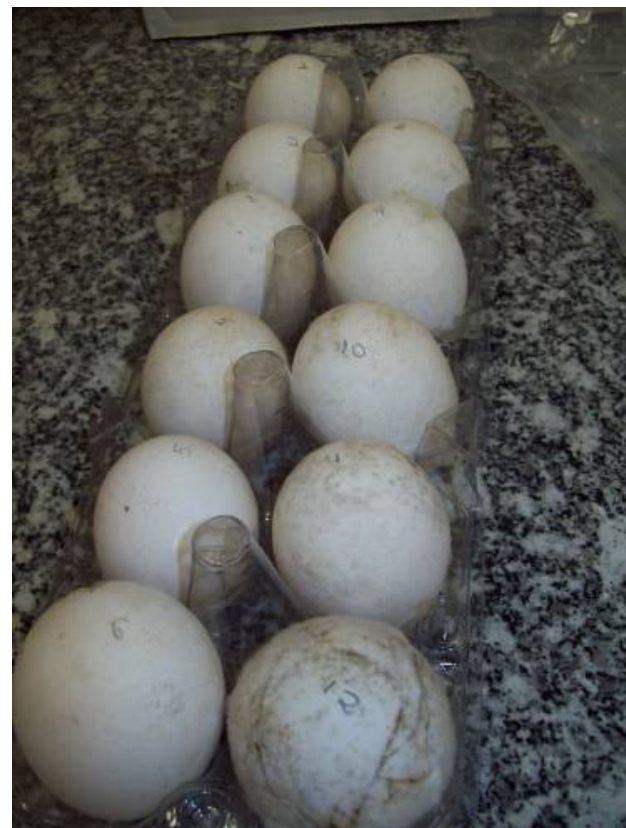

Figura 1. Aparência externa de ovos em condição de vácuo parcial. (Eggs external appearance in partial vacuum condition).

de avaliação os ovos em condição de vácuo com sachês sequestrantes mostraram notas para a aparência externa da casca estatisticamente igual a das embaladas na forma normalmente comercializada (filme PVC).

Para melhor entendimento, a figura 1 mostra cascas de ovos em condição de vácuo parcial aos 28 dias de armazenamento que, como já citado, foram as piores situações de desenvolvimento de fungos.

Na tabela III observa-se que a embalagem dos ovos em condição de vácuo novamente proporcionou piores notas no que diz respeito ao odor da casca do ovo. Isto é, ao $14^{\circ}$ e $28^{\circ}$ dias odor de mofo foi percebido nas cascas dos ovos destas embalagens, sendo que no último dia de análise foram obtidas as piores notas $(\mathrm{p}<0,05)$.

A higienização não influenciou o odor externo da casca dos ovos em qualquer condição de embalagem. Porém, ovos higienizados ou não, tiveram suas notas mais baixas novamente quando embalados em condição de vácuo. E ainda para este atributo, as notas para ovos em condição de vácuo com sachês sequestrantes de $\mathrm{O}_{2}$ foram semelhantes $(p>0,05)$ aos embalados em filme plástico.

Na tabela IV são mostrados os desdobramentos das interações entre os três fatores estudados (período, embalagens e higienização) para a análise da aparência interna da casca dos ovos. Observa-se que a embalagem dos ovos em condição de

Tabela IV. Desdobramentos das interações entre período de armazenamento (dias) e embalagens ou higienização, e entre embalagens e higienização para aparência da casca interna dos ovos. (Interactions for storage period $x$ packaging, storage period $x$ sanitation, and packaging $x$ sanitation for the internal egg shell appearance.)

\begin{tabular}{|c|c|c|c|c|}
\hline & \multicolumn{4}{|c|}{ Período de armazenamento } \\
\hline & 7 & 14 & 21 & 28 \\
\hline \multicolumn{5}{|l|}{ Embalagem } \\
\hline Filme & $9,00^{\mathrm{Aa}}$ & $8,93^{\mathrm{Aa}}$ & $8,86^{\mathrm{Aa}}$ & $8,83^{A_{2}}$ \\
\hline Vácuo parcial & $7,28^{\mathrm{Ba}}$ & $5,75^{\mathrm{Bb}}$ & $4,00^{\mathrm{BC}}$ & $4,50^{\mathrm{BC}}$ \\
\hline Vácuo+Seq. & $\mathrm{O}_{2} 9,00^{\mathrm{Aa}}$ & $8,93^{\mathrm{Aa}}$ & $8,86^{\mathrm{Aa}}$ & $8,83^{A-}$ \\
\hline \multicolumn{5}{|l|}{ Higienização } \\
\hline Sim & $9,00^{\mathrm{Aa}}$ & $7,50^{\mathrm{Ab}}$ & $8,02^{A b}$ & $7,50^{\mathrm{At}}$ \\
\hline \multirow[t]{3}{*}{ Não } & $7,86^{\mathrm{Bab}}$ & $8,24^{\mathrm{Aa}}$ & $6,45^{\mathrm{Bc}}$ & $7,28^{\mathrm{At}}$ \\
\hline & \multicolumn{4}{|c|}{ Embalagem } \\
\hline & Filme & $\begin{array}{l}\text { Vácuo } \\
\text { parcial }\end{array}$ & & $\begin{array}{l}\text { Vácuo+ } \\
\text { Seq. }\end{array}$ \\
\hline \multicolumn{5}{|l|}{ Higienização } \\
\hline Sim & $8,92^{\mathrm{Aa}}$ & $6,17^{\mathrm{Ab}}$ & & $8,92^{\mathrm{Aa}}$ \\
\hline Não & $8,89^{\mathrm{Aa}}$ & $4,59^{\mathrm{Bb}}$ & & $8,87^{\mathrm{Aa}}$ \\
\hline \multicolumn{5}{|c|}{ 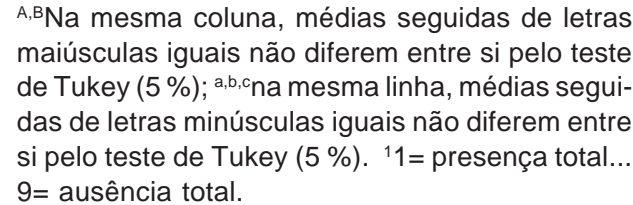 } \\
\hline
\end{tabular}




\section{CARACTERÍSTICAS SENSORIAIS DE OVOS EM DIFERENTES EMBALAGENS}

vácuo sempre proporcionou aparência interna de suas cascas piores $(\mathrm{p}<0,05)$ quando comparado aos ovos das embalagens filme e vácuo + sequestrante, principalmente a partir dos 14 dias de estocagem. Ovos não higienizados apresentaram queda na aparência interna de suas cascas já aos 7 dias de armazenamento, ou seja, emboloramento na parte interior da casca. Sendo que as piores aparências foram proporcionadas aos ovos não higienizados e anali- sados aos 21 dias de armazenamento.

Assim, ovos na embalagem em condição de vácuo parcial, quando não higienizados foram os que mostraram cascas mais emboloradas internamente, conforme ilustrado na figura 2.

Na tabela IV encontram-se os valores obtidos na análise sensorial quanto à aparência do albúmen (ApA) e da gema $(\mathrm{ApG})$, e do ovo inteiro (Ap - conjunto gema + ovo), bem como o odor dos ovos (OB, OA

Tabela $\boldsymbol{V}$. Médias das notas ${ }^{1}$ obtidas para aparência (Ap), odor de bolor (OB), odor de azedo $(O A)$, odor de podre (OP) no ovo inteiro, e aparência do albúmen e gema (ApA e ApG) dos ovos armazenados em diferentes embalagens. (Averages obtained for appearance (Ap), mold smell $(\mathrm{OB})$, sour smells $(\mathrm{OA})$ and rotten smell $(\mathrm{OP})$ in whole egg, and albumen and yolk appearance of eggs stored in different packaging).

\begin{tabular}{|c|c|c|c|c|c|c|}
\hline & \multicolumn{4}{|c|}{ Ovo inteiro } & \multirow{2}{*}{$\begin{array}{l}\text { Albúmen } \\
\text { ApA }\end{array}$} & \multirow{2}{*}{$\begin{array}{c}\text { Gema } \\
\text { ApG }\end{array}$} \\
\hline & Ap & $\mathrm{OB}$ & OA & OP & & \\
\hline \multicolumn{7}{|c|}{ Testemunha vs. fatorial } \\
\hline Testemunha & 9,00 & 9,00 & $9,00^{A}$ & $9,00^{A}$ & 9,00 & 9,00 \\
\hline Fatorial & 8,87 & 8,91 & $7,92^{\mathrm{B}}$ & $8,55^{\mathrm{B}}$ & 8,89 & 8,64 \\
\hline Teste F & $0,82^{\mathrm{NS}}$ & $0,55^{\mathrm{NS}}$ & $12,37^{\star *}$ & $7,78^{* *}$ & $0,84^{\mathrm{NS}}$ & $2,71^{\mathrm{NS}}$ \\
\hline \multicolumn{7}{|c|}{ Armazenamento em dias $(\mathrm{P})$} \\
\hline 7 & 9,00 & $9,00^{A}$ & - & - & 9,00 & - \\
\hline 14 & 8,86 & $8,98^{\mathrm{A}}$ & - & - & 8,86 & - \\
\hline 21 & 8,81 & $8,90^{A B}$ & - & - & 8,86 & - \\
\hline 28 & 8,83 & $8,78^{\mathrm{B}}$ & - & - & 8,83 & - \\
\hline Teste F & $2,39^{\mathrm{NS}}$ & $4,67^{\star \star}$ & - & - & $2,39^{N S}$ & - \\
\hline \multicolumn{7}{|l|}{ Embalagem (E) } \\
\hline Filme & 8,87 & 8,88 & - & - & 8,87 & - \\
\hline Vácuo parcial & 8,51 & 8,94 & - & - & 8,87 & - \\
\hline Vácuo+Seq. $\mathrm{O}_{2}$ & 8,87 & 8,92 & - & - & 8,87 & - \\
\hline Teste F & $0,19^{\text {NS }}$ & $0,48^{\mathrm{NS}}$ & - & - & $0,00^{\mathrm{NS}}$ & - \\
\hline \multicolumn{7}{|l|}{ Higienização (H) } \\
\hline Sim & 8,85 & 8,92 & - & - & 8,89 & - \\
\hline Não & 8,89 & 8,90 & - & - & 8,89 & - \\
\hline Teste F & $0,74^{\mathrm{NS}}$ & $0,07^{N S}$ & - & - & 0,00 & - \\
\hline F Int. PxE & $0,19^{\mathrm{NS}}$ & $0,40^{\mathrm{NS}}$ & $22,07^{* *}$ & $74,74^{* *}$ & 0,00 & $30,44^{* \star}$ \\
\hline F Int. PxH & $0,74^{\mathrm{NS}}$ & $0,07^{\mathrm{NS}}$ & $74,50^{* *}$ & $65,88^{* *}$ & 0,00 & $6,59^{* *}$ \\
\hline F Int. ExH & $0,74^{\mathrm{NS}}$ & $0,07^{\mathrm{NS}}$ & $15,34^{\star *}$ & $96,63^{* *}$ & 0,00 & $6,47^{* *}$ \\
\hline FInt. PxExH & $0,74^{\mathrm{NS}}$ & $0,07^{\mathrm{NS}}$ & $19,09^{\star *}$ & $104,67^{\star \star}$ & 0,00 & $6,94^{\star *}$ \\
\hline CV (\%) & 4,04 & 3,36 & 9,99 & 4,81 & 3,59 & 6,49 \\
\hline
\end{tabular}

Archivos de zootecnia vol. 62, núm. 240, p. 549. 


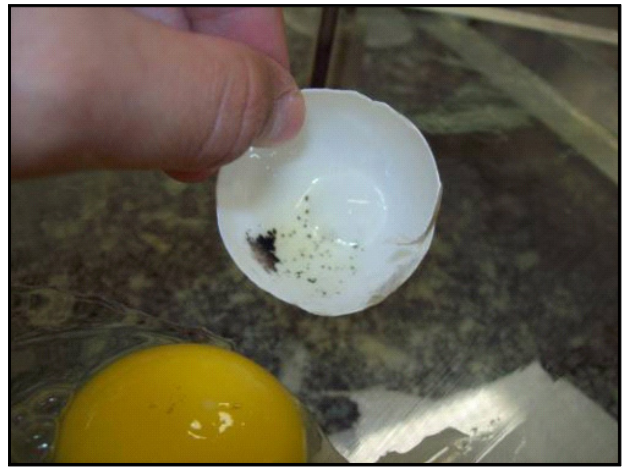

Figura 2. Aparência interna de ovos em condição de vácuo parcial. (Egg internal appearance in partial vacuum condition).

e OP, ou seja, odor de bolor, azedo e podre, respectivamente). Houve interação entre os fatores período de armazenamento $\mathrm{x}$ embalagem, período de armazenamento $\mathrm{x}$ higienização e entre embalagem $\mathrm{x}$ higienização para as características OA, OP e ApG, e todos os desdobramentos encontram-se nas tabelas VI a VIII.

Pelos resultados da tabela $\mathbf{V}$, observase que nenhum dos fatores estudados alterou ( $p>0,05)$ a aparência interna do ovo inteiro e a aparência do albúmen. Com relação ao odor de bolor, não foi percebido qualquer alteração até os 14 dias de armazenamento.

Os desdobramentos das interações para o odor característico de azedo dos ovos estão apresentados na tabela VI, onde notase que aos sete dias de armazenamento os odores dos ovos foram característicos para todos os tipos de embalagens e independente de terem sido higienizados ou não. Aos 14 dias de armazenamento, somente os ovos embalados em condição de vácuo + sequestrante de $\mathrm{O}_{2}$ apresentaram odor característico, e nesta embalagem os ovos não foram julgados com qualquer característica de odor azedo até o final do experimento. Ainda com relação ao odor azedo, também aos 14 dias de armazenamento, os ovos não higienizados apresentaram as menores notas $(p<0,05)$, invertendo tais médias aos 21 e 28 dias, ou seja, os higienizados mostram-se estatisticamente menores.

A higienização influenciou $(\mathrm{p}<0,05)$ apenas as médias dos ovos embalados em filme plástico, isto é, ovos não higienizados e embalados em filme plástico tiveram as menores notas de aceitação para o atributo odor azedo. Ovos embalados em condição de vácuo com sachês sequestrantes de $\mathrm{O}_{2}$, tiveram boa aceitação, quanto ao odor azedo, sendo eles higienizados ou não.

A tabela VII traz os desdobramentos das interações entre os três fatores estudados

Tabela VI . Desdobramentos das interações entre período de armazenamento (dias) $e$ embalagens ou higienização, e entre embalagens e higienização para odor azedo ${ }^{l}$ no interior dos ovos. (Interactions sliced of storage period $\mathrm{x}$ packaging, storage period $\mathrm{x}$ sanitation, and packaging $x$ sanitation for sour smells inside eggs).

\begin{tabular}{|c|c|c|c|c|}
\hline & \multicolumn{4}{|c|}{ Período de armazenamento } \\
\hline & 7 & 14 & 21 & 28 \\
\hline \multicolumn{5}{|l|}{ Embalagem } \\
\hline Filme & $9,00^{\mathrm{Aa}}$ & $6,21^{\mathrm{Bb}}$ & $8,86^{\mathrm{Aa}}$ & $8,42^{\mathrm{Aa}}$ \\
\hline Vácuo parcial & $9,00^{\mathrm{Aa}}$ & $6,36^{\mathrm{Bb}}$ & $6,18^{\mathrm{Bb}}$ & $6,00^{\mathrm{Bb}}$ \\
\hline Vácuo+Seq. $\mathrm{O}_{2}$ & ${ }_{2} 9,00^{\mathrm{Aa}}$ & $9,00^{\mathrm{Aa}}$ & $8,86^{\mathrm{Aa}}$ & $8,42^{\mathrm{Aa}}$ \\
\hline \multicolumn{5}{|l|}{ Higienização } \\
\hline Sim & $9,00^{\mathrm{Aa}}$ & $8,95^{\mathrm{Aa}}$ & $7,43^{\mathrm{Bb}}$ & $7,13^{\mathrm{Bb}}$ \\
\hline \multirow[t]{3}{*}{ Não } & $9,00^{\mathrm{Aa}}$ & $5,43^{\mathrm{BC}}$ & $8,50^{\text {Aab }}$ & $7,92^{\mathrm{Ab}}$ \\
\hline & \multicolumn{4}{|c|}{ Embalagem } \\
\hline & Filme & $\begin{array}{l}\text { Vácuo } \\
\text { parcial }\end{array}$ & & $\begin{array}{l}\text { Vácuo+ } \\
\text { Seq. } \mathrm{O}_{2}\end{array}$ \\
\hline \multicolumn{5}{|l|}{ Higienização } \\
\hline Sim & $8,80^{\mathrm{Aa}}$ & $6,96^{\mathrm{Ab}}$ & & $8,63^{\mathrm{Aa}}$ \\
\hline Não & $7,45^{\mathrm{Bb}}$ & $6,81^{\mathrm{AC}}$ & & $8,88^{\mathrm{Aa}}$ \\
\hline
\end{tabular}

A,BNa mesma coluna, médias seguidas de letras maiúsculas iguais não diferem entre si pelo teste de Tukey (5\%); a,b,cna mesma linha, médias seguidas de letras minúsculas iguais não diferem entre si pelo teste de Tukey $(5 \%) . \quad{ }^{1} 1=$ presença total... $9=$ ausência total. 


\section{CARACTERÍSTICAS SENSORIAIS DE OVOS EM DIFERENTES EMBALAGENS}

Tabela VII. Desdobramentos das interações entre período de armazenamento (dias) $e$ embalagens ou higienização, e entre embalagens e higienização para odor podre $e^{1}$ no interior dos ovos. (Interactions sliced of storage period $x$ packaging, storage period $x$ sanitation, and packaging $x$ sanitation for rotten smells inside eggs).

\begin{tabular}{|c|c|c|c|c|}
\hline & \multicolumn{4}{|c|}{ Período de armazenamento } \\
\hline & 7 & 14 & 21 & 28 \\
\hline \multicolumn{5}{|l|}{ Embalagem } \\
\hline Filme & $9,00^{\mathrm{Aa}}$ & $8,93^{\mathrm{Aa}}$ & $8,86^{\mathrm{Aa}}$ & a $8,83^{\mathrm{Aa}}$ \\
\hline Vácuo parcial & $9,00^{\mathrm{Aa}}$ & $8,43^{\mathrm{Ab}}$ & $8,86^{\text {Aab }}$ & b $8,75^{\text {Aab }}$ \\
\hline Vácuo+Seq. $\mathrm{O}_{2}$ & ${ }_{2} 9,00^{\mathrm{Aa}}$ & $5,39^{\mathrm{Bb}}$ & $8,86^{A a}$ & a $8,77^{\text {Aa }}$ \\
\hline \multicolumn{5}{|l|}{ Higienização } \\
\hline Sim & $9,00^{\mathrm{Aa}}$ & $6,55^{\mathrm{Bb}}$ & $8,86^{\mathrm{Aa}}$ & a $8,78^{\mathrm{Aa}}$ \\
\hline \multirow[t]{3}{*}{ Não } & $9,00^{\mathrm{Aa}}$ & $8,62^{\mathrm{Aa}}$ & $8,86^{\mathrm{Aa}}$ & $8,79^{\text {Aa }}$ \\
\hline & \multicolumn{4}{|c|}{ Embalagem } \\
\hline & Filme & $\begin{array}{l}\text { Vácuo } \\
\text { parcial }\end{array}$ & & $\begin{array}{l}\text { Vácuo+ } \\
\text { Seq. O }\end{array}$ \\
\hline \multicolumn{5}{|l|}{ Higienização } \\
\hline Sim & $8,92^{\mathrm{Aa}}$ & $8,84^{\mathrm{Aa}}$ & & $7,12^{\mathrm{Bb}}$ \\
\hline Não & $8,89^{\text {Aa }}$ & $8,67^{\text {Aa }}$ & & $8,89^{\mathrm{Aa}}$ \\
\hline
\end{tabular}

$\mathrm{A}, \mathrm{B} \mathrm{Na}$ mesma coluna, médias seguidas de letras maiúsculas iguais não diferem entre si pelo teste de Tukey ( $5 \%)$; a,b,cna mesma linha, médias seguidas de letras minúsculas iguais não diferem entre si pelo teste de Tukey ( $5 \%)$. ${ }^{11} 1=$ presença total.. $9=$ ausência total.

para o atributo odor podre no interior dos ovos. E de acordo com os dados, as piores médias para odor dos ovos com relação a odor podre foram obtidas aos 14 dias de armazenamento nos ovos embalados em condição de vácuo + sequestrante de $\mathrm{O}_{2}$. Estes mesmos ovos quando higienizados apresentaram notas mais baixas quando comparadas aos demais $(\mathrm{p}<0,05)$.

Na tabela VIII, observa-se que aos 21 dias de armazenamento, as gemas dos ovos embalados em condição de vácuo parcial foram as que apresentaram notas mais baixas para a aparência. E quando higienizados, esses ovos mostraram gemas com aparência inferior se comparados aos ovos das outras embalagens, higienizados ou não higienizados.

Semelhante aos dados obtidos aqui, Scatolini-Silva et al. (2010) ao estudarem embalagem à vácuo como alternativa para manutenção da qualidade de ovos armazenados em condições de ambiente, observaram que as embalagens vácuo e vácuo+ sílica foram as que mostraram ovos com melhores resultados, porém o aspecto visual destas embalagens, e consequentemente dos ovos destas, não foi satisfa-

Tabela VIII. Desdobramentos das interações entre período de armazenamento (dias) e embalagens ou higienização, e entre embalagens e higienização para aparência da gema ${ }^{1}$ dos ovos. (Interactions sliced of storage period $\mathrm{x}$ packaging, storage period $\mathrm{x}$ sanitation, and packaging $x$ sanitation for the yolk appearance).

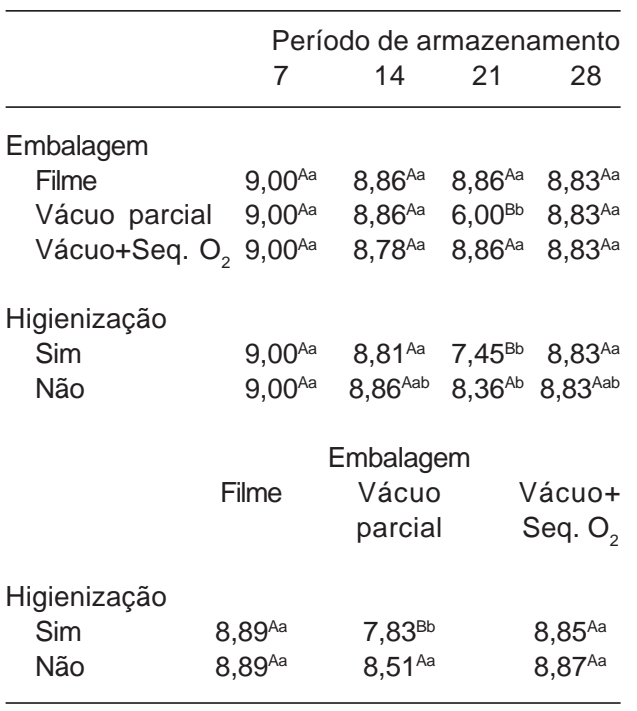

A,B $\mathrm{Na}$ mesma coluna, médias seguidas de letras maiúsculas iguais não diferem entre si pelo teste de Tukey ( $5 \%$ ); ;,b,c na mesma linha, médias seguidas de letras minúsculas iguais não diferem entre si pelo teste de Tukey $(5 \%) .{ }^{1} 1=$ presença total... $9=$ ausência total. 
tório, já que a maioria das cascas apresentaram-se com desenvolvimento de fungos. Em todos os períodos de armazenamento observou-se que a aparência normal do albúmen predominou. Porém, ovos embalados à vácuo+sílica/absorvedor e vácuo+ absorvedor não apresentaram albumina opaca em nenhum dos períodos de armazenamento. Diante de todas as observações encontradas no estudo citado, as embalagens vácuo+sílica/absorvedor de $\mathrm{O}_{2}$ e vácuo+absorvedor de $\mathrm{O}_{2}$ apresentaram aspecto visual das cascas, do albúmen e da gema (pós quebra) melhores. Porém em se tratando de qualidade interna, a embalagem vácuo+absorvedor de $\mathrm{O}_{2}$ preservou a qualidade do albúmen (UH) com melhor eficácia em relação à embalagem vácuo+ sílica/absorvedor de $\mathrm{O}_{2}$, isto é, mais próximas de um ovo fresco, como citado por Murakami et al. (1994) ao dizer que ovos frescos e com qualidade apresentam albú-

\section{BIBLIOGRAFIA}

Brasil. 1990. Portaria $\mathrm{n}^{\circ} 01$, de 21 de fevereiro de 1990. Oficializa as Normas Gerais de Inspeção de Ovos e Derivados. Diário Oficial, Brasília. 44. pp. 4321 (Seção1, de 06/03/1990).

Dutcosky, S.D. 1996. Análise sensorial de alimentos. Champagnat. Curitiba. 123 pp.

Fraga, M.E.; Curvello, F.A. e Rosa, C.A.R. 2007. Isolamento de fungos em ovos tipo comercial . Rev Bras Med Vet, 29: 37-38.

Frazier, W.C. y Westhoff, D.C. 2000. Microbiología de los alimentos. 4. ${ }^{a}$ ed. Acribia. Zaragoza. 681 pp.

Griswold, R.M. 1972. Estudos experimentais dos alimentos. Edgard Blugher. Handbook number 75. 2000. Rio de Janeiro. 56 pp.

Hawthorn, J. 1983. Fundamentos de ciência de los alimentos. Acribia. Zaragoza. pp. 114-122.

Kussakawa, K.C.K.; Furakami, A.E. e Furlan, A.C. 1998. Combinações de fontes de cálcio em rações de poedeiras na fase final de produção e após muda forçada. Rev Bras Zootecn. 27: 3.

Murakami, A.E.; Barriviera, V.R.; Scapinello, C.; men límpido, transparente, consistente, denso e alto, com pequena porção mais fluida.

\section{CONCLUSÕES}

Os ovos foram rejeitados pela aparência externa e interna, e odor externo da casca, quando em condição de vácuo parcial, principalmente se não higienizados; ainda em condição de vácuo parcial, foi percebido odor azedo e gemas opacas; na condição de vácuo+sachês sequestrantes de $\mathrm{O}_{2}$ foram notados odores podre, principalmente quando higienizados.

Os ovos embalados em filme de PVC foram os que mostraram melhores aceitações em todos os atributos avaliados, independente de terem sido higienizados ou não.

\section{AGRADECIMENTOS}

À FAPESP pelo financiamento da pesquisa.

Barbosa, M.J.B.; Ribeiro, R. e Valerio, S.R. 1994. Efeito da temperatura e do período de armazenamento sobre a qualidade interna do ovo de codorna japonesa (Coturnix coturnix japonica) para consumo humano. Rev Unimar, 16: $13-25$.

SAS Institute. 1999. SAS user's guide: statistics. Release 8.02. Cary. USA.

Scatolini-Silva, A.M.; Borba, H.; Giampietro, A.; Boiago, M.M.; Souza, T.A. e Souza, P.A. 2010. Embalagem à vácuo como alternativa para manutenção da qualidade de ovos armazenados em condições de ambiente. VIII Congresso de Produção e Comercialização de Ovos. Anais... Associação Paulista de Avicultura. São Pedro, SP. pp. 273-275.

Soares, L.A.S. e Siewerdt, F. 2005. Aves e ovos. Ed. Da Universidade UFPEL. Pelotas. 138 pp.

Stone, H.; Sidel, J.L.; Oliver, S.; Woosley, A. and Singleton, R.C. 1974. Sensory evaluation by quantitative descriptive analysis. Food TechnolChicago, 28: 24-34. 